\title{
Video Article \\ Data Collection on Marine Litter Ingestion in Sea Turtles and Thresholds for Good Environmental Status
}

\author{
Marco Matiddi ${ }^{1}$, Giuseppe A. deLucia ${ }^{2}$, Cecilia Silvestri ${ }^{1}$, Gaëlle Darmon ${ }^{3}$, Jesús Tomás ${ }^{4}$, Christopher K. Pham ${ }^{5}$, Andrea Camedda ${ }^{2}$, \\ Frederic Vandeperre ${ }^{5,6}$, Françoise Claro $^{7}$, Yakup Kaska ${ }^{8}$, Helen Kaberi ${ }^{9}$, Ohiana Revuelta ${ }^{4}$, Raffaella Piermarini ${ }^{1}$, Roberto Daffina ${ }^{1}$, Marco Pisapia $^{1}$, \\ Daniela Genta ${ }^{1}$, Doğan Sözbilen ${ }^{8}$, Mohamed N. Bradai ${ }^{10}$, Yasmina Rodríguez ${ }^{5}$, Delphine Gambaiani ${ }^{3}$, Catherine Tsangaris $^{9}$, Olfa Chaieb ${ }^{10}$, \\ Judicaëlle Moussier ${ }^{7}$, Ana L. Loza ${ }^{11}$, Claude Miaud ${ }^{3}$, INDICIT consortium ${ }^{12}$ \\ ${ }^{1}$ Italian National Institute for Environmental Protection and Research (ISPRA) \\ ${ }^{2}$ Institute for Coastal Marine Environment-National Research Council (IAMC-CNR) \\ ${ }^{3}$ EPHE, PSL Research University, UMR 5175 CE3FE, CNRS, UM, Univ P. Valery, SupAgro, IRD, INRA, Biogéographie et Écologie des Vertébrés \\ ${ }^{4}$ Cavanilles Institute of Biodiversity and Evolutionary Biology, University of Valencia \\ ${ }^{5}$ Departamento de Oceanografia e Pescas, Instituto do Mar/Okeanos, Universidade dos Açores \\ ${ }^{6}$ MARE - Marine and Environmental Sciences Centre, Universidade dos Açores \\ ${ }^{7}$ Muséum national d' Histoire naturelle (MNHN) \\ ${ }^{8}$ Sea Turtle Research and Application Center (DEKAMER), Pamukkale University \\ ${ }^{9}$ Institute of Oceanografy Hellenic Centre for Marine Research (HCMR) \\ ${ }^{10}$ Institut National des Sciences et Technologies de la Mer (INSTM) \\ ${ }^{11}$ University of Las Palmas de Gran Canaria \\ ${ }^{12}$ INDICIT consortium
}

Correspondence to: Marco Matiddi at marco.matiddi@isprambiente.it

URL: https://www.jove.com/video/59466

DOI: doi:10.3791/59466

Keywords: Environmental Sciences, Issue 147, Sea turtle, plastic ingestion, necropsy, marine litter, MSFD, EcAp process, good environmental status, thresholds

\section{Date Published: 5/18/2019}

Citation: Matiddi, M., deLucia, G.A., Silvestri, C., Darmon, G., Tomás, J., Pham, C.K., Camedda, A., Vandeperre, F., Claro, F., Kaska, Y., Kaberi, H., Revuelta, O., Piermarini, R., Daffina, R., Pisapia, M., Genta, D., Sözbilen, D., Bradai, M.N., Rodríguez, Y., Gambaiani, D., Tsangaris, C., Chaieb, O., Moussier, J., Loza, A.L., Miaud, C., , I.c. Data Collection on Marine Litter Ingestion in Sea Turtles and Thresholds for Good Environmental Status. J. Vis. Exp. (147), e59466, doi:10.3791/59466 (2019).

\section{Abstract}

The following protocol is intended to respond to the requirements set by the European Union's Marine Strategy Framework Directives (MSFD) for the D10C3 Criteria reported in the Commission Decision (EU), related to the amount of litter ingested by marine animals. Standardized methodologies for extracting litter items ingested from dead sea turtles along with guidelines on data analysis are provided. The protocol starts with the collection of dead sea turtles and classification of samples according to the decomposition status. Turtle necropsy must be performed in authorized centers and the protocol described here explains the best procedure for gastrointestinal $(\mathrm{Gl})$ tract isolation. The three parts of the $\mathrm{GI}$ (esophagus, stomach, intestine) should be separated, opened lengthways and contents filtered using a $1 \mathrm{~mm}$ mesh sieve. The article describes the classification and quantification of ingested litter, classifying GI contents into seven different categories of marine litter and two categories of natural remains. The quantity of ingested litter should be reported as total dry mass (weight in grams, with two decimal places) and abundance (number of items). The protocol proposes two possible scenarios to achieve the Good Environmental Status (GES). First: "There should be less than $\mathrm{X} \%$ of sea turtles having $\mathrm{Y} \mathrm{g}$ or more plastic in the $\mathrm{Gl}$ in samples of 50-100 dead turtles from each sub-region", where $\mathrm{Y}$ is the average weight of plastic ingested and $\mathrm{X} \%$ is the percentage of sea turtles with more weight (in grams) of plastic than $\mathrm{Y}$. The second one, which considers the food remain versus plastic as a proxy of individual health, is: "There should be less than $\mathrm{X} \%$ of sea turtles having more weight of plastic (in grams) than food remains in the $\mathrm{Gl}$ in samples of 50-100 dead turtles from each sub-region".

\section{Video Link}

The video component of this article can be found at https://www.jove.com/video/59466/

\section{Introduction}

Marine litter is a complex issue to address since it can enter the oceans via multiple sources and forms. Over $80 \%$ of the litter that is encountered in marine environments is made up of plastic ${ }^{1}$. The role of this material from an economic perspective has been increasing in the last 50 years. As a consequence, its production has also increased twentyfold since 1960, reaching 335 million tons in 2016 . This value is expected to double over the next 20 years ${ }^{2}$. Moreover, it has been estimated that around 5 to 13 million tons of plastic end up in the oceans every year (which is equal to 1.5 to $4 \%$ of global plastic production) ${ }^{2,3}$. Plastic movement is influenced by its physical properties (e.g., buoyancy) 
or environmental variables (e.g., tide and stream), and plastic can be accumulated in all marine compartments ${ }^{4,5}$. To face the plastic problem, it is important to bear in mind that, as many other environmental issues, it is transboundary and therefore governance solutions are complex to meet $^{6}$. To better reach this goal we must take into consideration regional and international frameworks, so as to enhance or maintain marine environmental awareness and protection across the globe ${ }^{7}$. The final objective of the European Union's Marine Strategy Framework Directive (MSFD) is to achieve a Good Environmental Status (GES) in European waters by 2020, to protect marine biodiversity, and to promote the sustainable use of marine environments. This will be done through 11 qualitative descriptors, of which Descriptor 10 focuses on marine litter and is defined as "Properties and quantities of marine litter do not cause harm to the coastal and marine environments". Within this descriptor, the New Commission Decision ${ }^{8}$ decided to add criteria D10C3-"The amount of litter and micro-litter ingested by marine animals is at a level that does not adversely affect the health of the species concerned"-since it was considered to be a relevant criteria in the evaluation of GES. As a result, member states were requested to produce a list of species, to develop methodological standards and define threshold values through regional or sub-regional cooperation.

After the first scientific publication in $1838^{9}$, on the Storm-Petrel with an ingested candle stick, over 500 marine species have been listed for ingesting marine litter ${ }^{10,11,12,13,14}$, and sea turtles were among the first taxa recorded to ingest plastic debris ${ }^{15}$. Given their propensity for ingesting litter, their wide distribution and the large range of habitats used during their life, sea turtles, in particular the loggerhead species Caretta caretta (Linnaeus 1758), was chosen as a potential indicator for the Mediterranean basin ${ }^{16}$, like the sea bird Fulmarus glacialis (Linnaeus, 1761) for Northern European waters ${ }^{17}$. Even after five decades of research, discussion of method standardization has been very limited ${ }^{18}$ and a cohesive approach by the scientific community to quantify plastic ingestion by wildlife is lacking ${ }^{19}$. Standardized sampling protocols, and analytical detection methods and metrics to assess plastic ingestion by marine biota are needed; a recent paper showed the potential benefits and limitations of using marine species as bio-indicators on plastic pollution ${ }^{20}$. Following the Matiddi et al. proposal in $2011^{21}$ to use the loggerhead as bio-indicator, and the Technical Group on Marine Litter Report ${ }^{22}$, a specific protocol to consider marine litter ingested by sea turtle has been developed and tested by ten partners in seven countries in the Mediterranean Sea and Atlantic Ocean within the European Project INDICIT (GA $\left.n^{\circ} 11.0661 / 2016 / 748064 / S U B / E N V . C 2\right)$. This protocol provides standardized methodologies for the analysis of marine litter ingested by sea turtles in order to support the new Commission Decision $(E U)^{8}$, Criteria D10C3, where threshold values are requested. According to the definition provided by $\mathrm{COM}^{8}$, the threshold value is a number or a range that allows to evaluate if the quality level criterion was achieved, therefore helping in assessing the GES. The proposed protocol for assessing the litter ingested by sea turtles, will be useful in gathering data on the composition and abundance of litter and evaluate its impact on marine environments. Moreover, collecting this type of standardized data will help to define threshold values. Here we consider two types of scenarios. The first scenario takes into account the Fulmar litter EcoQO monitoring, which is implemented for the OSPAR area: "There should be less than X\% of sea turtles having Y g or more plastic in the Gl in samples of $50-100$ dead turtles from each sub-region, where $Y$ is the average weight of plastic ingested considering all the samples and $X \%$ is the percentage of sea turtles with more weight (in grams) of plastic than Y. The second one aims at considering a proxy of individual health level: "There should be less than $\mathrm{X} \%$ of sea turtles having more weight of plastic (in grams) than food remains in the Gl in samples of 50-100 dead turtles from each subregion", where the weight of ingested plastic is compared with food remaining in each individual.

\section{Protocol}

A series of "basic" and "optional" parameters are proposed to be collected. The basic parameters correspond to the minimum parameters fundamental to accomplish the Criteria D10C3, while the optional parameters allow acquiring more knowledge on sea turtles' behavior/biology.An observation data sheet and a list of material necessary for sampling individuals in the field and analysis of litter in the laboratory are provided here in order to facilitate data recording and statistical analysis by following a standardized table. Marine litter subcategories are chosen according to the shape and type of items. Remains of sea turtle's food and anything natural that are non-food items (stone, wood, pumice, etc.) are requested for considering thresholds and the animal's diet. All the experimental activities of this protocol have been conducted on dead turtles according to the law of the involved countries and international rules. All the necropsies must be performed at the authorized centres.

\section{Sampling from carcass: fill the observation sheet (Appendix 1 in Supplementary Files 1 and 2)}

1. Fill in the contact details including name, contact (phone, mail) and institution of the observer(s) (data collector).

2. Identify the species as follows: Cc (Caretta caretta, Linnaeus 1758); Dc (Dermochelys coriacea, Vandelli 1761); Cm (Chelonia mydas, Linnaeus 1758); Ei (Eretmochelys imbricata, Linnaeus 1766); Lo (Lepidochelys olivacea, Eschscholtz 1829); Lk (Lepidochelys Kempii, Garman 1880); Nd (Natator depressus, Garman 1880).

3. Tags: If a tag already exists on the flipper, specify the number ( $\mathrm{N}^{\circ}$. Indicate the presence and number of electronic chips. Otherwise, note NO.

4. Specify the animal identification code. For example: "two letters for the country"_"two letters for the location (e.g., region or institution)"_"YY" "MM"."DD"_"chip number".

5. Note the date of discovery ( $\mathrm{yy} / \mathrm{mm} / \mathrm{dd})$.

6. Specify the location of discovery which is the recovery area or coordinates in decimal degrees.

7. Report the specimen's body condition level: $\mathbf{1}$ (Alive), $\mathbf{2}$ (Fresh -dead recently), $\mathbf{3}$ (Partially decomposed -internal organs are still in good condition), 4 (Advanced decomposed-skin scales are raised or lost), 5 (Mummified-part of the skeleton or part of the body are missing). See Figure 1.

8. Discovery circumstances: Note the circumstances among the four categories: Stranding (animal found on the beach or on the shoreline); By-catch/Fisheries (animal captured actively by fishermen, e.g., ingestion of a hook, trapped in a net, brought back by fishermen, etc.); Found at sea (animal discovered on the sea surface); Dead at the recovery centre (the animal arrived alive, but died during its recovery). 

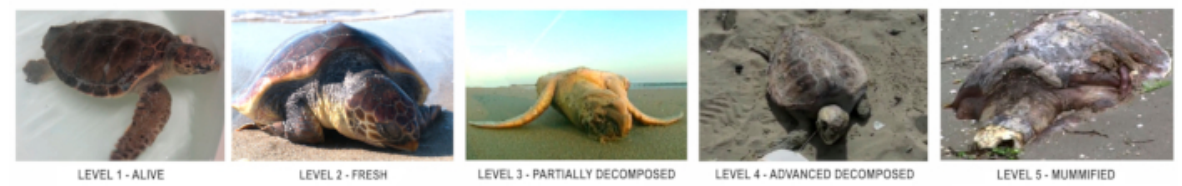

Figure 1: Specimen's body condition level or decomposition status. Please click here to view a larger version of this figure.

\section{Sea turtle necropsy: biometrics measurements and extraction of the contents of the gastro-intestinal tract}

1. Arrange for the transport of the animal to the authorized center for necropsy. In case of an extremely decomposed animal, assess the integrity of the digestive tract before disposal at the authorized center. If the necropsy cannot be done immediately after the recovery, freeze the carcass at $-20^{\circ} \mathrm{C}$.

2. Before the necropsy operation, record the biometric measurements in the specific section of the recovery file. The curved carapace length, notch to tip ${ }^{23}$, is mandatory; the other measures are optional (e.g., curved carapace width, weight).

3. Conduct an external examination of the animal body and report the information in the specific section of the necropsy file. Also inspect the oral cavity for possible presence of foreign material.

4. Separate and remove the plastron from the carapace by making an incision along the edge as highlighted by the yellow line (Figure 2a).

5. Use a short blade or cut with a horizontal tilt avoiding damaging the interior parts (Figure $\mathbf{2} \mathbf{b}-\mathbf{c}$ ). The ligament attachment to the pectoral and pelvic girdle must be cut when the plastron is detached from the carapace so that it is easy to access and handle it.

6. Expose the gastro-intestinal (GI) tract removing the pectoral muscles and the heart of the turtle (Figure 2d).

7. (Optional) Assess the trophic status qualitatively by evaluating the atrophy of pectoral muscles (none-moderate-severe) and fat thickness in the articular cavities and on the coelomic membrane (abundant-normal-low-none).

8. Extract the $\mathrm{Gl}$ and place it on the examination table. Do this with two operators to make the actions easier. While one operator keeps the carcass laying on one side, the other separates the ligaments from the different organs and the membranes from the carapace using small blades or scissors and removes the Gl from the animal (Figure 2f).

9. Isolate the esophagus, stomach and intestine using plastic clamps. Place these on the esophagus close to the mouth, at the esophageal valve, on the peg and at the cloacae, as close as possible to the anal orifice as indicated by yellow arrows (Figure 2f).

10. Record the sex of the animal when possible.

11. Separate the esophagus, stomach and intestine definitively by placing a second clamp (corresponding to the cutting point) to avoid spillage of the contents.

12. Open the $\mathrm{Gl}$ section lengthwise using a scissor (or the fingers when possible), and then directly place the material contained into a $1 \mathrm{~mm}$ mesh sieve by cleaning the GI walls with running water.

13. Take note of each anomaly in the GI (e.g., ulcers, perforations, adhesions, inflammation).

14. Inspect the contents in the sieve to eventually detect any tar, oil, or fragile material that must be removed and treated separately.

15. Rinse the contents through the sieve in order to remove the liquid portion, mucus and unidentifiable digested matter.

16. Repeat the sequence for each GI portion separately.

17. Freeze all the material collected by the sieves or store it in jars containing $70 \%$ alcohol solution. NOTE: For more details on the anatomy of the sea turtle see also Wyneken $(2001)^{24}$.
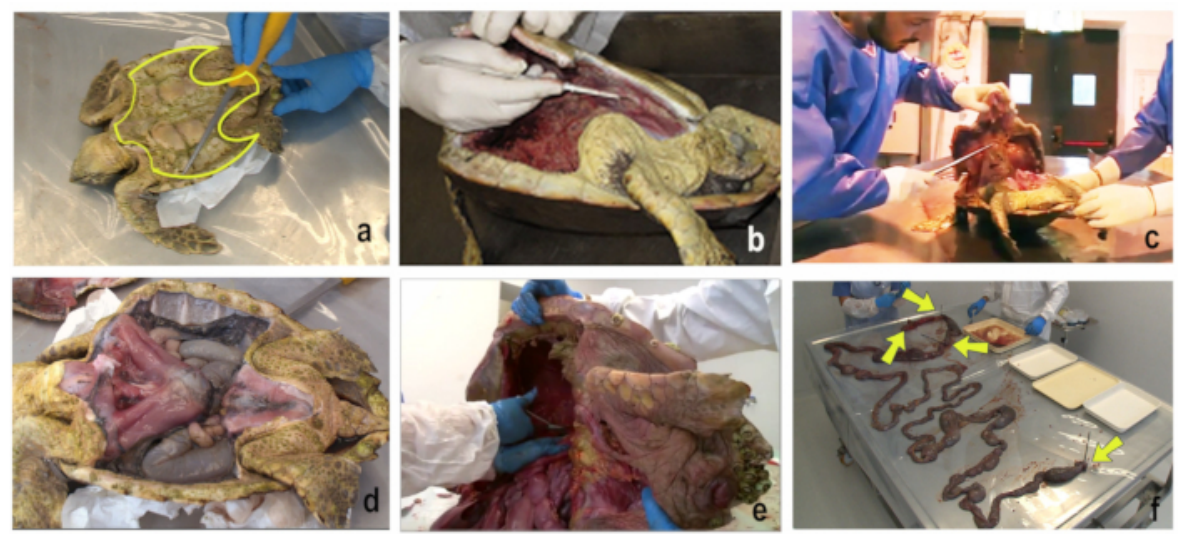

Figure 2: Sequence of turtle necropsy. (a) Ventral view of a dead turtle. The yellow line indicates the way to cut in order to separate the plastron from the rest of the turtle. (b,c) Horizontal cuts to prevent affecting the interior organs. (d) Ventral view of the opened turtle. (e) Extraction of the GI tract. (f) View of the entire GI, yellow arrows indicate where clamps must be attached in order to separate the three different GI sections. Please click here to view a larger version of this figure.

\section{Data collection and analysis: marine litter classification}

1. Label the sample code and the respective GI section.

2. Empty the jars on a $1 \mathrm{~mm}$ mesh sieve, gathering all the material.

3. Rewash the collected material with water in order to eliminate alcohol and clean the litter. 
4. Separate marine litter from the organic components or other materials, identifying the category of marine litter by visual analysis, sorting the material on a Petri dish, and sub-diving the collected items into the different categories.

5. Fill up the datasheet with collected information.

6. Use the stereomicroscope to take a closer look at any unidentifiable materials.

7. Dry the marine litter at room temperature or in an oven at $35^{\circ} \mathrm{C}$ for $12 \mathrm{~h}$.

8. Dry the organic fraction in an oven at $35^{\circ} \mathrm{C}$ for $12 \mathrm{~h}$ or in a drier.

9. Report the number and the dry weight of the different categories of marine litter.

10. Report the dry weight of the organic fraction subdivided into food remain(s) and natural non-food remain(s). Total dry mass (weight in grams, accurate to the $2^{\text {nd }}$ decimal place) is the main information used in the monitoring program, followed by the number of items (abundance).

11. Record other information such as the color of the items, volume of litter, different incidences of litter in the esophagus, stomach and intestine, and incidence per litter category as this is useful for research and impact analysis. The raw data will provide varied information for each single section of the $\mathrm{Gl}$; the total contents of the marine litter within the three parts will be accounted for in the final data.

\section{Representative Results}

This protocol, derived from the MSFD guideline ${ }^{22}$ and has been co-built and improved by more than 50 stakeholders (biologists from rescue centers, stranding networks, veterinarian and research laboratories) from 7 countries across the Mediterranean and the European Atlantic coasts, it proposes a homogenized, feasible and easy evaluation of litter ingestion by sea turtles. The protocol has been tested on loggerhead turtles, and most of the manipulations are also applicable to other sea turtle species. The first important result of this protocol is the description of marine litter items under seven categories according to their visual features (Figure 3). This classification has been derived by the Fulmar $\mathrm{EcoQo}^{17,25}$, and modified as per the authors' experience in sea turtle ecology. The first category, and usually the least abundant one, is industrial plastic (IND PLA) comprised of plastic pellet and granules, usually cylindrical and round shape, but also oval or cubical shapes, rarely found to be ingested by the loggerhead turtle ${ }^{16,26}$. The second category comprises the remains of sheet-like (USE SHE) materials, such as plastic bags, agricultural sheets or plastic foil. They appear in irregular shapes but are always thin and flexible. The third category includes ropes, filaments, and other threadlike materials such as the remains of ghost fishing gear usually made of nylon (USE THR). The fourth category includes all foamed plastics (USE FOA) such as polystyrene foam or foamed soft rubber. The fifth category includes fragments of hard plastic items (USE FRA). Fragments are highly abundant in the GI contents and they can be found in a variety of different colors. They are derived from broken larger pieces and are usually rigid, with an irregular shapes and sharp crooked edges. Any other plastic items including elastics, dense rubber, balloon pieces, and soft air-gun bullets, are categorized as other user plastic (USE POTH). All the non-plastic marine litter such as cigarette butts, newspapers, rubbish and hard pollutant are included in the last category of litter other than plastic (OTHER) even if they are not easily found in sea turtles. The other two categories not classified as marine litter, are (i) remains of the turtle natural diet (FOO) and (ii) any natural item, not recognized as prey for the sea turtle such as stone, wood or pumice (NFO).

Figure 4 shows an example of representative results on the dry mass of marine litter categories, where sheet-like plastic (USE SHE) was the most abundant class, and plastic bags or parts of them, were the main ingested items. Similar results are shown in Figure $\mathbf{5}$ in terms of the number of items (abundance). Table 1 shows an example result of litter dry mass analysis in six different areas, which is useful for setting the threshold value according to the requirements from the European Union's MSFD. These areas should be represented, for example, by countries or sub-region of the Mediterranean basin. The reported average is calculated using all individuals examined, including samples without ingested marine litter. According to our example, area 5 represented the clearest zone of the Mediterranean basin and the data from this area could be used to set the threshold value to be reached. For this area the first scenario could be: "There should be less than $\mathbf{2 5 \%}$ of sea turtles having $\mathbf{0 . 5}$ $\mathbf{g}$ or more plastic in the $\mathrm{GI}$ in samples of 50-100 sea turtles". The second scenario could be: "There should be less than $\mathbf{3 2} \%$ of sea turtles having more plastic grams than food remains (FOO) in the GI in samples of 50-100 sea turtles".

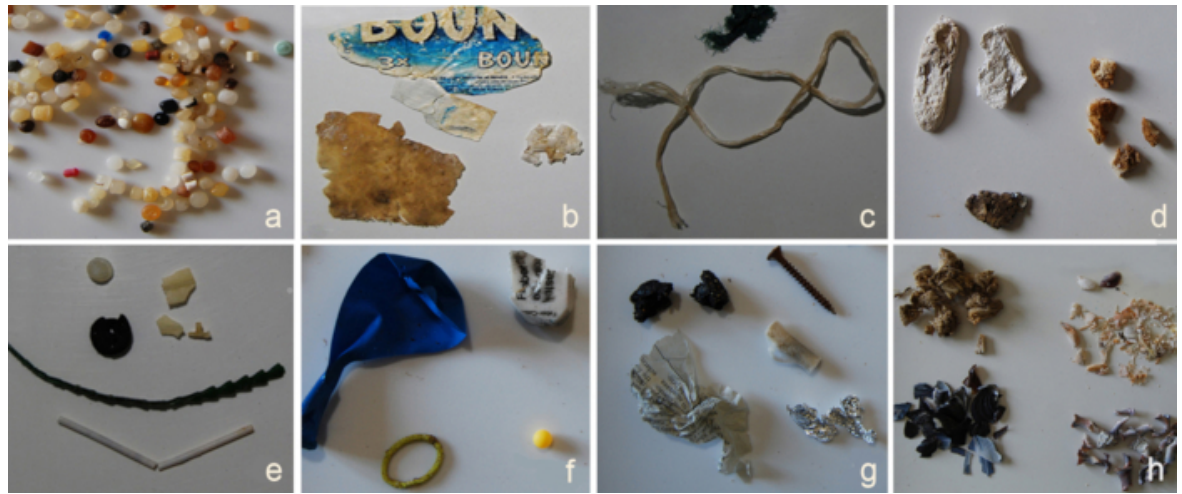

Figure 3: Examples of marine litter categories established for marine turtle ingestion monitoring. (a) IND PLA, (b) USE SHE, (c) USE THR, (d) USE FOA, (e) USE FRA, (f) USE POTH, (g) OTHER, (h) FOO. Please click here to view a larger version of this figure. 


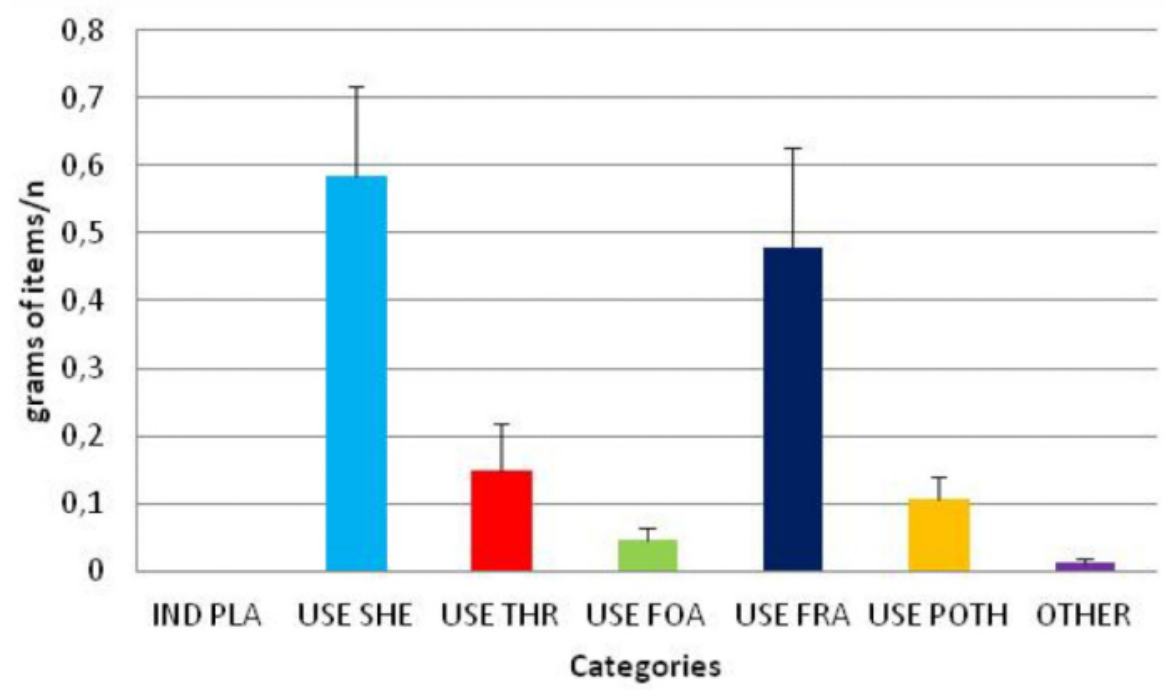

Figure 4: Example results of weights of marine litter ingested by sea turtles under the various categories. The average weight values are reported in grams of items per individual $( \pm \mathrm{SE})$. Please click here to view a larger version of this figure.

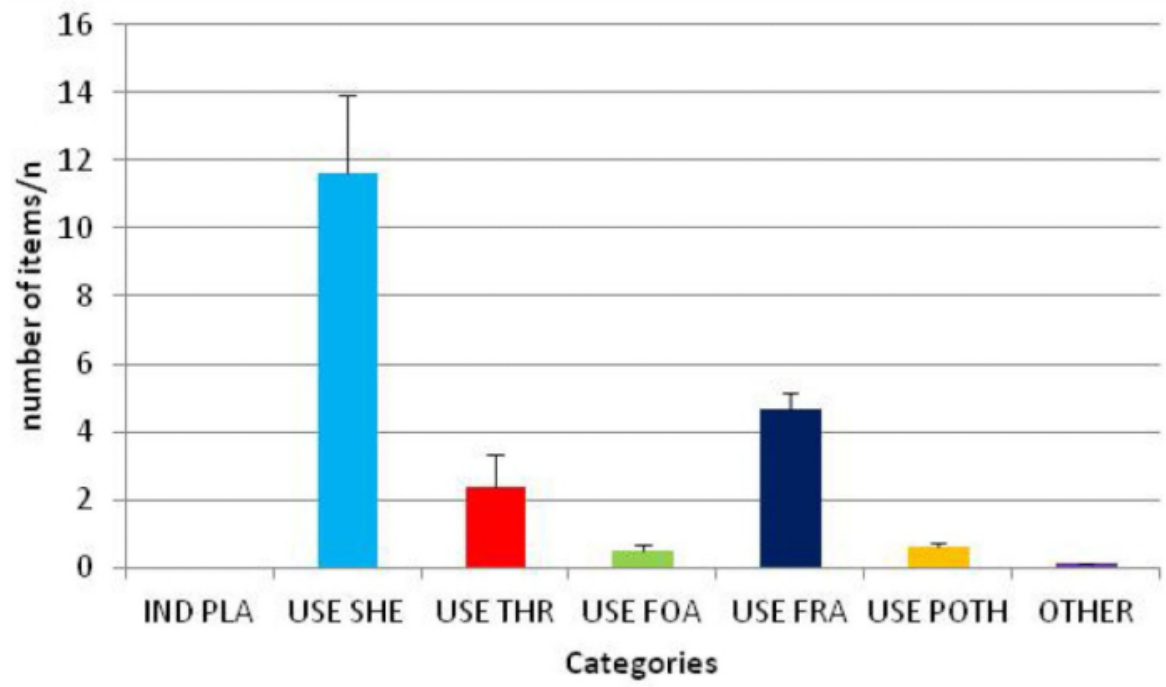

Figure 5: Example results for the number of marine litter categories ingested by sea turtles. The average number of items per individual $( \pm$ $\mathrm{SE})$ are reported. Please click here to view a larger version of this figure.

\begin{tabular}{|l|l|l|l|l|}
\hline AREA & Sample size $(\mathbf{n})$ & $\begin{array}{l}\text { Average value } \mathbf{s E} \text { for dry } \\
\text { weight of ingested plastic } \\
\mathbf{( g )}\end{array}$ & $\begin{array}{l}\text { Percentage of turtles with } \\
\text { more plastic than average } \\
\text { value }(\%)\end{array}$ & $\begin{array}{l}\text { Percentage of turtles with } \\
\text { more plastic than food } \\
\text { remain }(\%)\end{array}$ \\
\hline $\mathbf{1}$ & 100 & $1.32 \pm 0.03$ & 27 & 64 \\
\hline $\mathbf{2}$ & 100 & $1.61 \pm 0.01$ & 28 & 67 \\
\hline $\mathbf{3}$ & 100 & $1.35 \pm 0.02$ & 26 & 62 \\
\hline $\mathbf{4}$ & 95 & $0.73 \pm 0.02$ & 34 & 40 \\
\hline $\mathbf{5}$ & 65 & $0.55 \pm 0.03$ & 25 & 32 \\
\hline $\mathbf{6}$ & 50 & $0.90 \pm 0.04$ & 44 & 54 \\
\hline
\end{tabular}

Table 1: Example of results from different areas (e.g., countries, sub-regions, etc.), using dry mass of marine litter. Please click here to download this table as an excel file.

Supplementary Files 1. Please click here to download this file.

Supplementary Files 2. Please click here to download this file. 
Discussion

This protocol allows evaluation of the total abundance of marine litter, and identification of the main litter categories ingested by sea turtles. It is less expensive compared to other monitoring programs with sea activities because sea turtles could be collected after stranding on the beach or be recovered by fishermen. The identification of marine litter categories is easy and rapid as the lower limit on item size is $1 \mathrm{~mm}$. A limitation of the protocol is the use of sea turtle considering that all 7 species of marine turtles are listed on Appendix I of the Convention on International Trade in Endangered Species of Wild Fauna and Flora ${ }^{27}$; therefore, only authorized personnel can handle live and dead animals or parts of them. Turtle management and recovery should be reported and coordinated with the corresponding authorities. Sanitary precautions must be taken when handling dead or alive wild animals to minimize risks of zoonosis. This protocol has been tested on loggerhead species but it is applicable to all the seven turtle species. Data analysis should be carried out separately for each species. The specimen's body conditions as considered under five levels from alive to mummified turtles. Level 1 (Alive) is considered for a more detailed classification of the specimen's body condition in case the turtle died at the rescue center after the recovery. The protocol is applicable to dead individuals from levels 2 to 4 , but also on individuals that died after recovery (circumstances: dead at the recovery center). Levels 2 and 3 are adequate for the protocol while level 4 allows to measure biometrics data and assessing the presence/absence of ingested litter for the evaluation of frequency of occurrence (FO\%), and the percentage of turtles with ingested marine litter on the entire sample. Individuals of level 5, where generally the gastrointestinal content has been lost cannot be considered for the collection and quantification of litter ingestion. Taking photos of the animal before handling, could provide additional information on the sample as the probable cause of death or main injuries and entanglement. It is important to include a scale bar on the pictures. Even if often sea turtles had fishing hooks in their $\mathrm{Gl}$, data do not have to be included in the analysis because fishing hooks on which longline victims are actively caught are not considered as "marine litter". Hook presence should be recorded in the notes. Collection of data should be performed separately in each part of the GI (esophagus, stomach, intestine), in order to evaluate the degree of tolerance to marine litter ingestion considering GI blockage or the capability to eliminate it through defecation, as demonstrated in previous studies $^{16,28,29,30,31,32}$. A critical step of the protocol could be found in the collection of the number of items. Multiple pieces could be derived from fragmentation of the same object inside the GI or as a consequence of separate ingestion. Subjective interpretation of a single item or multiple separate pieces could correspond to a potential bias in recording number (Figure 6). For this reason, threshold values have been elaborated using only ingested marine litter mass data, like the Fulmar EcoQO ${ }^{17,25}$.

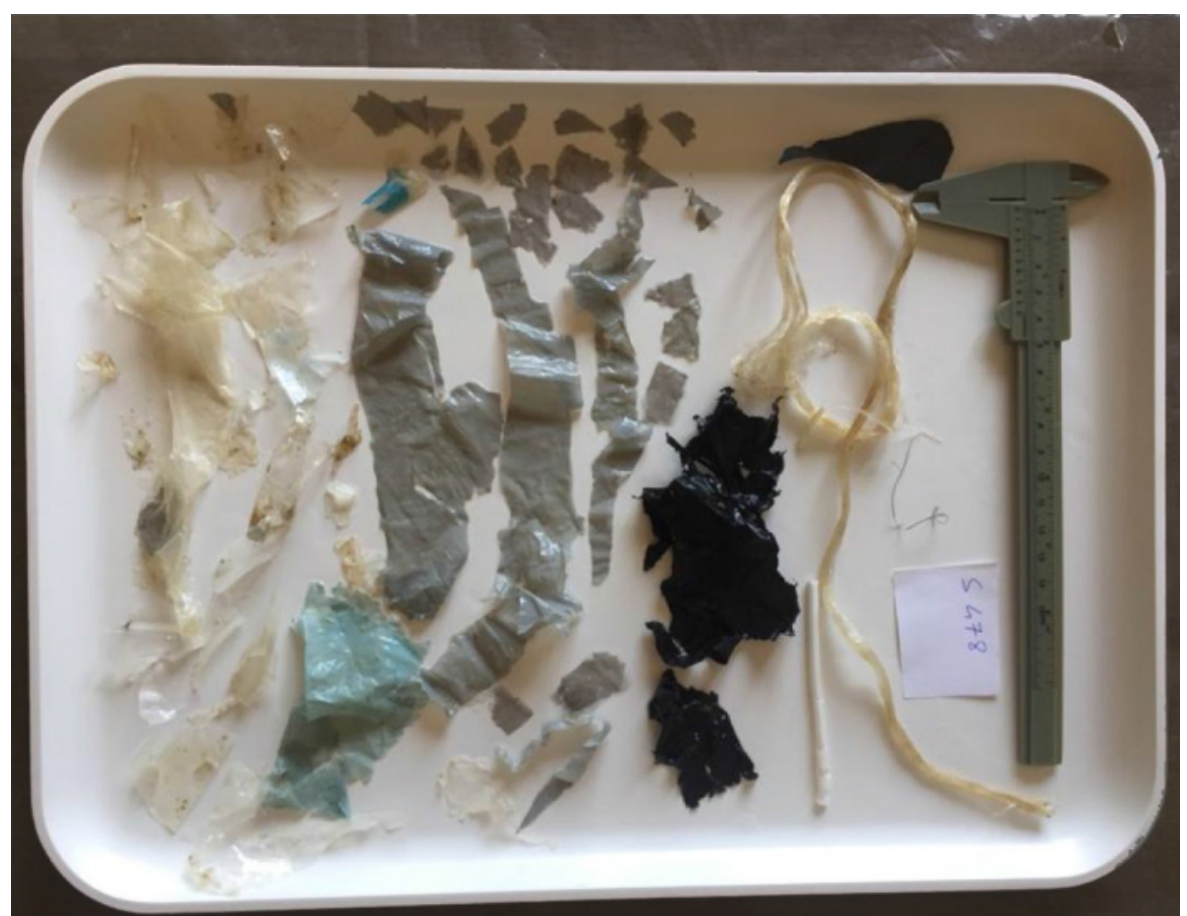

Figure 6: Fragmentation of single items could occur before ingestion or during the feeding process, producing bias in counting. Please click here to view a larger version of this figure.

The protocol requires the categorization of different plastic items according to their shapes (USE SHE, USE THR). This sub-division is useful to identify the source of marine litter with a list of items according to their abundance. It aides policy makers in their programs of measures, providing rapid evidence of their efficiency in targeting items by evaluating their strength. For example, the ban of plastic bags in the markets should correspond to a reduction of USE SHE category ingested (Figure 4, Figure 5) in sea turtle samples collected in the future. The application of this protocol will allow EU member states to answer to the MSFD requirements, evaluating their own baselines and defining the threshold values at which GES is achieved. Thresholds should be determined in pristine or next to pristine areas. Due to the ubiquity of plastic in the marine environment, a pristine area does not exist. According to the example data (Table 1), area 5, was the clearest zone and could represent the value $(\mathbf{Y})$ to be reached for the Mediterranean basin. Member states should decide thresholds according to the significant reduction of their own distance from this value. According to a recent review ${ }^{18}$, marine litter ingestion units should be normalized to the size of the turtle, especially if the goal is to compare different age classes. Nevertheless, a relationship between the mass of ingested litter and turtles size has been detected by different authors with positive, negative or zero values ${ }^{16,26,32,33,34}$. Our protocol does not include animal size in the first scenario, but it could be possible to estimate the body burden, evaluating mass of the turtle using curved carapace length (CCL) ${ }^{35}$ and use the 
ratio of weight of plastic weight of turtle instead of only grams of ingested plastic $(\mathrm{Y})$. In any case we suggest verifying any possible significant differences before merging oceanic stage turtles with neritic ones or early juveniles with adults, in order to better stratify the samples ${ }^{16,26}$. The second scenario is more related to the individual health status and could better answer to the Criteria D10C3: "The amount of litter and microlitter ingested by marine animals is at a level that does not adversely affect the health of the species concerned". In fact, impact of ingested plastic items consists most frequently in sub-lethal effects rather than lethal ones ${ }^{28,36,37,38,39}$. We also rarely found an occlusion or a perforation due to plastic ingestion, which could cause the death of the turtles. Sub-lethal effects are not easy to be detected and to be distinguished from impacts due to other pollutants ${ }^{40}$. Dietary dilution or assimilation of contaminants happens when marine litter is inside the $\mathrm{Gl}$ of the turtle ${ }^{41}$. Thus the sample with more grams of plastic than food remains could indicate an animal in a very bad health condition. In order to remain in line with the Fulmar EcoQO ${ }^{17,25}$ used by the northern European countries, both scenarios consider plastic weight instead of marine litter weight.

Finally it is important to clarify the differences between (i) analyzing the ingestion of plastic in sea turtles as indicator of impact on population with consequences for population conservation and (ii) analyzing the ingestion of plastic in sea turtles as bio-indicator of impact on the coastal and marine environment ${ }^{20,40}$. To understand the implications of this impact on conservation of turtles population, more information is needed and better data stratification is necessary ${ }^{42}$. By confronting the opinion of 35 specialists from 13 nations, who are experts in sea turtle biology and conservation, it is clear that sea turtles have been widely studied across the years, although it is still necessary to investigate the interactions with human activities and therefore assess the population status and potential threats ${ }^{43}$.

This means that a single protocol cannot be considered as exhaustive for all the thematic and more studies are necessary to understand the impact of plastic at population level.

Even tough plastic could be considered to cause a low level of damage to sea turtles, with respect to by-catch or habitat destruction, its reduction has been challenging in the last few years and quick methods of measurement must be elaborated. There is a controversy in the use of stranded turtles for monitoring purposes because, according to some authors they are not representative of the whole population ${ }^{40}$, while others have declared that stranded turtles do not represent a bias of marine litter ingestion rates in the background population ${ }^{44}$. Moreover, in many countries there is not a well-organized stranding network or system linking rescue centers to fishermen and there is a lack of information on by-catch and post release mortality by fisheries. Hence, stranded samples cannot always be considered as sick turtles without normal feeding behavior for a time period before dying and reaching the beach; many of them are "death at sea" turtles washed ashore and are usually used as samples in monitoring activities ${ }^{26,32,38,45}$. We believe that stranded samples are useful in providing information on the level of marine litter abundance in the environment and we suggest excluding only turtles with completely empty gastrointestinal tract from this analysis as they could be sick from a long time before death. The use of this protocol would enable evaluation of environmental status and marine litter availability for marine organisms. It could also be helpful in improving our knowledge on turtle behavior. The significance of the method with respect to the MSFD TSML guidelines ${ }^{22}$, is due to the harmonization in seven countries and the number of samples on which it has been tested $(n=700)$. Specimen's body condition level has been defined and marine litter ingested categories have been reduced according to the preliminary results. Moreover, this is the first time representative results have been shown and connected to the GES thresholds.

The protocol is an efficient tool for researchers to understand the impact of plastic on the marine environment, globally or at a local scale, and for comparing standardized data with neighboring countries. This result could not be reached before, due to the discrepancies in data among different countries, preventing any spatial comparison.

\section{Disclosures}

The authors have nothing to disclose.

\section{Acknowledgments}

Authors are grateful to the French Rescue Centres (Jean-Batiste Senegas), stranding networks (Jacques Sacchi) and veterinarian laboratories (Joanne Belfort) and Jessiaca Martin and Marie Sabatte, Cetacean and sea turtle stranding network of the Valencia Community, including the Marine Zoology Unit of the Cavanilles Institute (University of Valencia) and the Biodiversity Service of the Generalitat Valenciana, the Portuguese Regional Fund for Science and Technology of the Azores (Maria Vale), the Italian Rescue Centres (Stazione Zoologica "Anton Dohrn" Naples and Sardinian CREs) the veterinarian laboratories (IZSLT M. Aleandri Roma; IZSAM G. Caporale Teramo; IZSS G. Pegreffi Otistano;. IZS CReTaM Palermo), members of the INDICIT Advisory Board and the PO for their suggestion, and the Environmental Ministries and Regional Governments of the participant countries for their support.

Two anonymous reviewers for their suggestions and comments.

The present protocol has been performed by INDICIT consortium in the frame of the European DG-ENV project GA No. 11.0661/2016/748064/ SUB/ENV.C2.

1. UNEP. Marine plastic debris and microplastics - Global lessons and research to inspire action and guide policy change. United Nations Environment Programme, Nairobi (2016).

2. COM/2018/028. Communication From The Commission To The European Parliament, The Council, The European Economic And Social Committee And The Committee Of The Regions A European Strategy For Plastics In A Circular Economy. (2018).

3. Jambeck, J.R., et al. Plastic waste inputs from land into the ocean. Science. 347,768-771 (2015).

4. Mansui, J., Molcard, A., Ourmieres, Y. Modelling the transport and accumulation of floating marine debris in the Mediterranean basin. Marine Pollution Bulletin. 91, 249-257 (2015).

5. Law, K.L. Plastics in the Marine Environment. Annual Review Marine Science. 9, 205-229 (2017). 
6. Vince, J. and Hardesty, B.D. Plastic pollution challenges in marine and coastal environments: from local to global governance. Restoration Ecology., 25 (1), 123-128 (2017).

7. Bürgi, E. Sustainable Development in International Law Making and Trade: International Food Governance and Trade in Agriculture. Edward Elgar Publishing (2015).

8. COMMISSION DECISION (EU) 2017/848 of 17 May 2017 laying down criteria and methodological standards on good environmental status of marine waters and specifications and standardized methods for monitoring and assessment, and repealing Decision 2010/477/EU. (2017).

9. Provencher, J.F., et al., Quantifying ingested debris in marine megafauna: a review and recommendations for standardization. Analytical Methods. 9, 1454 (2017).

10. CBD - Secretariat of the Convention on Biological Diversity and the Scientific and Technical Advisory Panel—GEF. Impacts of Marine Debris on Biodiversity: Current Status and Potential Solutions, Montreal. Technical Series No. 67 (2012).

11. Kühn, S., Rebolledo, E.L.B., Van Franeker, J.A. Deleterious effects of litter on marine life. In Marine Anthropogenic Litter. Edited by Bergmann, M., Gutow, L., Klages, M., Springer, 75-116 (2015).

12. Derraik, J. G. The pollution of the marine environment by plastic debris: a review. Marine Pollution Bulletin. 44, 842-852 (2002).

13. Gall, S. C., Thompson, R. C. The impact of debris on marine life. Marine Pollution Bulletin. (2015).

14. Laist, D. W. Overview of the biological effects of lost and discarded plastic debris in the marine environment. Marine Pollution Bulletin. 18, 319-326 (1987).

15. Fritts, T. H. Plastic bags in the intestinal tracts of leatherback marine turtles. Herpetological Review. 13, 72-73 (1982).

16. Matiddi, M. et al. Loggerhead Sea Turtles (Caretta caretta): a Target Species for Monitoring Litter Ingested by Marine Organisms in the Mediterranean Sea. Environmental Pollution. 230, 199-209 (2017).

17. van Franeker, J., et al. Monitoring plastic ingestion by the northern fulmar Fulmarus glacialis in the North Sea. Environmental Pollution. 159, 2609-2615 (2011).

18. Lynch, J.M. Quantities of marine debris ingested by sea turtles: global meta-analysis highlights need for standardized data reporting methods and reveals relative risk. Environmental Science \& Tecnology. 52 (21), 12026-12038 (2018).

19. Provencher, J. et al. Quantifying ingested debris in marine megafauna: a review and recommendations for standardization. Analytical Methods. 9, 1454 (2017).

20. Bonanno, G. and Orlando-Bonaca, M. Perspectives on using marine species as bioindicators of plastic pollution. Marine Pollution Bulletin. 137, 209-221 (2018).

21. Matiddi, M., van Franeker, J.A., Sammarini, V., Travaglini, A., Alcaro, L. Monitoring litter by sea turtles: an experimental protocol in the Mediterranean. Proceedings of the 4th Mediterranean Conference on Sea Turtles. (2011).

22. MSFD-TSGML. Guidance on monitoring of marine litter in European Seas. A guidance document within the common implementation strategy for the marine strategy framework directive. EUR-26113 EN. JRC Scientific and Policy Reports JRC83985. http://mcc.jrc.ec.europa.eu/ documents/201702074014.pdf (2013).

23. Bolten, A.B. Research and Management Techniques for the Conservation of Sea Turtles. In IUCN/SSC Marine Turtle Specialist Group Publication. Edited by Eckert, K. L,. Bjorndal, K. A., Abreu-Grobois, F. A.,Donnelly, M. 4 (1999).

24. Wyneken, J. The Anatomy of Sea Turtles U.S. Department of Commerce NOAA Technical Memorandum NMFS SEFSC 470. https:// www.sefsc.noaa.gov/turtles/TM_470_Wyneken.pdf. (2001).

25. van Franeker, J.A., Meijboom, A. Litter NSV, Marine Litter Monitoring by Northern Fulmar; a Pilot Study. Alterra-rapport. vol. 401 (2002).

26. Domènech, F., Aznar, F.J., Raga, J.A., Tomás J. Two decades of monitoring in marine debris ingestion in loggerhead sea turtle, Caretta caretta, from the western Mediterranean. Environmental Pollution. 244, 367-378 (2018).

27. CITES-Convention on International Trade in Endangered Species of Wild Fauna and Flora. Annex I (2019).

28. Tomas, J., Guitart, R., Mateo, R., Raga, J.A. Marine debris ingestion in loggerhead sea turtles, Caretta caretta, from the Western Mediterranean. Marine Pollution Bulletin. 44, 211-216 (2002).

29. Nelms, S.E., et al. Plastic and marine turtles: a review and call for research. ICES Journal of Marine Science. 73 (2), 165-181, (2015).

30. Fukuoka, T. et al. The feeding habit of sea turtles influences their reaction to artificial marine debris. Scientific Reports. 6 (28015), (2016).

31. Hoarau, L., Ainley, L., Jean, C., Ciccione, S. Ingestion and defecation of marine debris by loggerhead sea turtles, Caretta caretta, from bycatches in the South-West Indian Ocean. Marine Pollution Bulletin. 84, 90-96 (2014).

32. Nicolau, L., Marçalo, A., Ferreira, M., Sa S., Vingada J., Eira C. Ingestion of marine litter by loggerhead sea turtles, Caretta caretta, in Portuguese continental waters. Marine Pollution Bulletin. 103, 179-185 (2016).

33. Pham, C.K. et al. Plastic ingestion in oceanic-stage loggerhead sea turtles (Caretta caretta) off the North Atlantic subtropical gyre. Marine Pollution Bulletin. 121, 22-229 (2017).

34. Clukeya, K.E., et al. Investigation of plastic debris ingestion by four species of sea turtles collected as bycatch in pelagic Pacific longline fisheries. Marine Pollution Bullettin. 120 (1-2), 117-125 (2017).

35. Wabnitz, C., Pauly, D. Length-weight relationship and additional growth parameters for sea turtles. In Von Bertalanffy growth parameters of non-fish marine organisms. Edited by the Fisheries Centre, University of British Columbia. 16, 92-101, (2008).

36. Bjorndal, K.A. Foraging ecology and nutrition in sea turtles. In The Biology of Sea Turtles. Edited by Lutz, P.L., Musick, J.A. CRC Marine Science Series. CRC Press, Boca Raton, 199-231 (1997).

37. McCauley, S.J., Bjorndal, K.A. Conservation implications of dietary dilution from debris ingestion: sublethal effects in post-hatchling loggerhead sea turtles. Conservation Biology. 13, 925-929 (1999).

38. Campani, T., et al. Presence of plastic debris in loggerhead turtle stranded along the Tuscany coasts of the Pelagos sanctuary for mediterranean marine mammals (Italy). Marine Pollution Bulletin. 74, 1330-1334 (2013).

39. Deudero, S. and Alomar C. Revising interactions of plastics with marine biota: evidence from the Mediterranean in CIESM 2014. In Marine litter in the Mediterranean and Black Seas. Edited by Briand, F. CIESM Workshop Monograph n 46 CIESM Publisher, Monaco (2014).

40. Fossi, C., et al., Bioindicators for monitoring marine litter ingestion and its impacts on Mediterranean biodiversity. Environmental Pollution. 237, 1023-1040 (2018)

41. Mccauley, S., Bjorndal, K. A. Conservation Implications of Dietary Dilution from Debris Ingestion: Sublethal Effects in Post-Hatchling Loggerhead Sea Turtles. Conservation Biology. 13, 925-929 (1999).

42. Casale, P., Freggi, D.,Paduano, V.,Oliverio, M. Biased and best approaches for assessing debris ingestion in sea turtles, with a case study in the Mediterranean. Marine Pollution Bulletin. 110 (1), 238-249 (2016).

43. Hamann, M. et al. Global research priorities for sea turtles: informing management and conservation in the 21st century. Endangered Species Research. 11, 245-269 (2010). 
44. Schuyler, Q.A. et al. Risk analysis reveals global hotspots for marine debris ingestion by sea turtles. Global Change Biology. 22, 567-576. 13078 (2016).

45. Camedda, A. et al. Interaction between loggerhead sea turtles (Caretta caretta) and marine litter in Sardinia (Western Mediterranean Sea). Marine Environmental Research. 100, 25-32 (2014). 